\title{
Estradiol and Progesterone have Opposing Roles in the Regulation of Fear Extinction in Female Rats
}

\author{
Bronwyn M Graham*,1 and Melissa Daher' \\ 'School of Psychology, The University of New South Wales Australia, Sydney, NSW, Australia
}

Fear extinction, the laboratory basis of exposure therapy for anxiety disorders, fluctuates across the female rat estrous cycle, where extinction is enhanced during proestrus (high estradiol and progesterone), and impaired during metestrus (low estradiol and progesterone). During the estrous cycle increasing levels of estradiol precede and then overlap with increased levels of progesterone. We sought to isolate the impact of these hormonal changes on fear extinction by systematically treating ovariectomized female rats with estradiol alone, or in combination with progesterone. We found that estradiol alone facilitated extinction recall, whereas the effects of progesterone on estradiol-treated rats were biphasic and dependent on the time interval between progesterone administration and extinction training. Progesterone potentiated estradiol's facilitation of extinction recall when extinction training occurred $6 \mathrm{~h}$ after progesterone administration. However, progesterone abolished estradiol's facilitation of extinction recall when extinction training occurred $24 \mathrm{~h}$ after progesterone administration. Furthermore, in naturally cycling rats, blocking progesterone receptor activation during proestrus (when progesterone levels peak) prevented the impairment in extinction recall in rats extinguished during metestrus. These results suggest that in naturally cycling females whereas cyclical increases in estradiol facilitate fear extinction, cyclical increases in progesterone may lead to fear extinction impairments. As extinction training took place after the hormonal treatments had been metabolized, we propose that genomic mechanisms may at least partly mediate the impact of cyclic fluctuations in sex hormones on fear extinction. Neuropsychopharmacology (2016) 4I, 774-780; doi: I0.I038/npp.2015.202; published online 5 August 2015

\section{INTRODUCTION}

Anxiety disorders like posttraumatic stress disorder are characterized by deficits in the ability to inhibit fear. Fear inhibition can be studied using fear extinction, a procedure in which subjects are repeatedly presented a fear-eliciting conditioned stimulus (CS, eg, a noise that was previously paired with shock) in the absence of aversive outcome until fear responses decline. Extinction recall is assessed the following day by measuring fear responses in the presence of the extinguished CS. Fear extinction forms the basis of exposure therapy, the current psychological treatment of choice for anxiety disorders. Investigating the behavioral and neurobiological processes that underpin fear extinction is thought to be a promising avenue through which novel means of augmenting the efficacy of exposure therapy can be identified (Graham and Milad, 2011).

Although a comprehensive cross-species model of the mechanisms underlying fear extinction has been developed, this model is grossly limited by the fact that it has been based on studies that have almost exclusively been conducted in males. Indeed, fear extinction has only been studied in

* Correspondence: Dr BM Graham, School of Psychology, The University of New South Wales Australia, Sydney, NSW 2052, Australia, Tel: +6I 29385 3886, Fax: +6I 29385364 I,

E-mail: bgraham@psy.unsw.edu.au

Received 22 April 2015; revised 5 July 2015; accepted 6 July 20I5; accepted article preview online 9 July 2015 females recently. This research has revealed that female rats exhibit markedly different extinction recall depending on when they were extinguished during the 4-day estrous (menstrual) cycle (Chang et al, 2009; Milad et al, 2009; Graham and Milad, 2013; Rey et al, 2014; Gruene et al, 2015). Specifically, female rats exhibit low fear responses at extinction recall only when extinguished during proestrus, when levels of the sex hormones estradiol and progesterone are high. Conversely, they exhibit return of fear at extinction recall when extinguished during metestrus, a period of low estradiol and progesterone levels.

Although it is clear that fluctuations in ovarian sex hormones modulate fear extinction, the exact role of each hormone is unknown. In the naturally cycling rat, following a period of low estradiol and progesterone, increases in estradiol precede and then overlap with increases in progesterone. Consequently, research with naturally cycling females cannot easily dissociate the distinct effects of these different hormonal phases on fear extinction. A common approach used by previous research aimed at understanding other effects of the estrous cycle is to surgically remove the gonads, thus eliminating the primary endogenous source of sex hormones. The hormones of interest can then be systematically replaced in a pattern that mimics the cyclic changes in these hormones. For example, Woolley and McEwen (1993) demonstrated that estradiol treatment alone in ovariectomized (OVX) female rats led to increased hippocampal dendritic spine densities within $48 \mathrm{~h}$, an effect 
that persisted for 6 days. When progesterone was administered 2 days after estradiol treatment, even greater increases in spine density were observed within $6 \mathrm{~h}$, but within $24 \mathrm{~h}$ spine density declined to basal levels. These results mirrored cyclic fluctuations in spine density in intact rats, where spine density is lowest during metestrus and greatest during proestrus. Woolley and McEwen (1993) inferred that in the naturally cycling rat, estradiol increases spine density, whereas progesterone initially augments and then rapidly attenuates estradiol's effects. This was supported by additional findings demonstrating that blocking progesterone receptor activation during proestrus prevented the subsequent decline in dendritic spine density in intact rats.

The study by Woolley and McEwen (1993), in addition to providing insight to the physiological consequences of fluctuating ovarian sex hormones, established an ecologically valid means of assessing the hormonal mechanisms underlying functional changes across the estrous cycle. The aim of the present study was to apply their method to identify how estradiol and progesterone interact to produce rapid cyclic changes in fear extinction in naturally cycling female rats. In our initial experiments, we examined the consequences of Woolley and McEwen's (1993) hormone treatment protocol on fear extinction in OVX rats. Following fear-conditioning OVX rats received estradiol, alone or in combination with progesterone. In experiment 1 , we determined whether estradiol alone could facilitate fear extinction when it was administered $48 \mathrm{~h}$ before extinction training. In experiment 2 , we assessed the impact of progesterone, administered 6 or $24 \mathrm{~h}$ before extinction training, on fear extinction in estradiol-treated rats. Finally, in experiment 3, we translated our findings from OVX to intact rats by assessing the impact of preventing progesterone receptor activation during proestrus in naturally cycling rats subsequently extinguished during metestrus. Combined, these approaches provide novel insights to the nature and time-course of estradiol and progesterone's effects on fear extinction in female rats.

\section{MATERIALS AND METHODS}

\section{Subjects}

Experimentally naïve Sprague-Dawley-derived female rats, aged 10-12 weeks, obtained from a commercial supplier (Animal Resources Centre, Perth, Australia), were used. Rats were housed in groups of eight in plastic cages $(67 \times 30 \times$ $22 \mathrm{~cm}^{3}$ ) in a $20-22^{\circ} \mathrm{C}$ colony room. They were maintained on a $12 \mathrm{~h}$ light-dark cycle (lights on at $0700 \mathrm{~h}$ ) with food and water available ad libitum. Procedures were approved by the Animal Care and Ethics Committee at UNSW Australia and followed guidelines outlined in The Australian Code Of Practice For The Care And Use Of Animals For Scientific Purposes (7th edition, 2004).

\section{Surgery}

In experiments 1 and 2 rats received bilateral ovariectomy (OVX). Rats were anesthetized with isoflurane (Laser Animal Health, Australia) mixed with oxygen. Bupivacaine (Cenvet, Australia) was applied to the skin before a dorsal midline incision was made caudal to the posterior border of the ribs. The abdominal wall muscles were separated and the periovarian fat was exposed to isolate the ovary, fallopian tube, and uterine horn. The fallopian tube was clamped and the ovary and oviduct removed. The uterine horn and periovarian fat were returned to the abdominal cavity and the incision was sutured and closed with wound clips. Immediately after surgery rats were injected i.m. with $0.15 \mathrm{ml}$ each of $100 \mathrm{mg} / \mathrm{ml}$ cephazolin and $300 \mathrm{mg} / \mathrm{ml}$ benacillen, and s.c. with $0.05 \mathrm{ml}$ of rimadyl (all from Cenvet, Australia). Rats were given 4-5 days recovery before behavioral training, during which time they were handled and weighed daily.

\section{Estrous Cycling}

In experiment 3, vaginal smears were conducted daily (between 0800 and $0010 \mathrm{~h}$ ) to determine estrous cycle phase in naturally cycling rats. This commenced 4 days before fear conditioning and ended the day of testing to ensure regular cycling throughout the experiment. A cotton-tip moistened with $0.9 \%$ saline was inserted into the vaginal canal and rapidly twisted to collect epithelial cells, which were transferred to a microscope slide, dyed with KwikDiff Stain Kit (Thermofisher, Australia), and inspected under a light microscope $(\times 10)$. Rats have a 4 -day cycle with distinct vaginal cytology in each phase (estrus, metestrus, diestrus, and proestrus). Phases were identified by the presence of leukocytes (metestrus/diestrus), nucleated cells (proestrus), and cornified cells (estrus), as outlined by Becker et al (2005).

\section{Hormone and Drug Administration}

In experiments 1 and 2, OVX rats received two s.c. injections of $\beta$-Estradiol (Sigma-Aldrich, Sydney, Australia; $10 \mu \mathrm{g}$ in $150 \mu \mathrm{l}$ sesame oil), or an equivalent volume of sesame oil. In experiment 2, rats received a single s.c. injection of progesterone (Sigma-Aldrich; $500 \mu \mathrm{g}$ in sesame oil), or an equivalent volume of sesame oil, administered after the second estradiol injection. In experiment 3, naturally cycling rats received two s.c. injections of the progesterone receptor antagonist RU486 (Sigma-Aldrich, Australia; $2 \mathrm{mg}$ in $0.2 \mathrm{ml}$ sesame oil), or an equivalent volume of sesame oil. The estradiol and progesterone doses were identical to those used by Woolley and McEwen (1993) and create physiological hormone levels that mimic those of naturally cycling rats during proestrus. The RU486 dose was used by Woolley and McEwen (1993) to block progesterone receptor activity during proestrus.

\section{Apparatus}

Four Med Associates experimental chambers $(24 \times 30 \times$ $21 \mathrm{~cm}^{3}$ ) were used for conditioning, extinction training, and recall. Chambers were housed in separate wooden cabinets to minimize external auditory and visual stimulation; ventilation fans provided low, constant background noise $(\sim 58 \mathrm{~dB})$. An infrared video camera mounted on the rear wall of the cabinets recorded the behavior of each rat inside the chamber. The chambers were divided into two sets that differed in visual and tactile features. The first set (designated context A) had front and rear walls and ceilings constructed of clear Perspex. The sidewalls were stainless steel, and one was embedded with a high-frequency speaker. The floor consisted of stainless steel rods $(4 \mathrm{~mm}$ diameter, 
spaced $16 \mathrm{~mm}$ apart center to center), connected to a shock generator, with a stainless steel tray of corn cob bedding $3.5 \mathrm{~cm}$ beneath. These chambers were illuminated by infrared light from the camera. The second set (designated context B) differed from context $\mathrm{A}$ in that the front walls were covered with patterned paper $(2.5 \mathrm{~cm}$ wide vertical black and white stripes), and the ceilings and stainless steel rod floor were overlaid with a sheet of opaque Perspex, below which was an empty stainless steel tray. White light from a table lamp positioned on top of the chambers provided illumination.

The CS was a white noise (4 $\mathrm{dB}$ above background noise) delivered through the sidewall speaker, and the US was a scrambled foot-shock ( $1 \mathrm{~s}, 0.6 \mathrm{~mA})$ delivered through the floor.

\section{Procedure}

Handling and context pre-exposure. Rats were handled for 4-5 min each day for three consecutive days; after handling on each day rats were individually placed in context $\mathrm{A}$ for $10 \mathrm{~min}$.

Fear conditioning. Conditioning was identical in all experiments. Rats were placed in context $\mathrm{A}$ and after a 2 min adaptation period the CS was presented for $10 \mathrm{~s}$ and coterminated with the shock US. Rats received three CS-US pairings (intertrial interval $85-135 \mathrm{~s}$, with an average of $110 \mathrm{~s})$. Conditioning occurred before hormone administration in experiments 1 and 2 , and during diestrus in experiment 3.

Hormone replacement/drug administration. In all experiments hormone/drug administration began the day after fear conditioning to avoid introducing potentially confounding effects on the acquisition or consolidation of learned fear. In experiment 1, two groups received two injections of estradiol or vehicle, spaced $24 \mathrm{~h}$ apart. In experiment 2 , three groups received two injections of estradiol, and one group received vehicle injections, spaced $24 \mathrm{~h}$ apart. Two days after the second estradiol or vehicle injection, two of the estradioltreated groups received progesterone (groups ' $\mathrm{E}+\mathrm{P} 6 \mathrm{~h}$ ' and ' $\mathrm{E}+\mathrm{P} 24 \mathrm{~h}$ '), whereas the third estradiol-treated group (group 'estradiol') and the vehicle group (group 'vehicle') received vehicle. In experiment 3, rats received two injections of RU486 (group 'RU486') or vehicle (groups 'proestrus' and 'metestrus') at 1300 and $1800 \mathrm{~h}$ during proestrus, the day after conditioning.

Extinction training. Extinction training in all experiments was identical. Rats were placed in context $B$ and after a $2 \mathrm{~min}$ adaptation period, received $6 \times 2$ min CS presentations, with an intertrial interval of $2 \mathrm{~min}$. In experiment 1 , extinction training occurred $48 \mathrm{~h}$ after the second injection. In experiment 2, extinction training occurred $6 \mathrm{~h}$ (group $\mathrm{E}+\mathrm{P}$ $6 \mathrm{~h}$ ), or $24 \mathrm{~h}$ (group $\mathrm{E}+\mathrm{P} 24 \mathrm{~h}$ ) after the progesterone administration. Half of groups vehicle and estradiol received extinction training $6 \mathrm{~h}$, and the other half $24 \mathrm{~h}$, after the final vehicle injection. After determining that there were no differences dependent on the time of extinction training (Supplementary Figure S1), data were collapsed to create two groups ('vehicle' and 'estradiol'). Thus, this design controlled for the different amounts of time elapsing between conditioning and extinction recall in the $\mathrm{E}+\mathrm{P} 24 \mathrm{~h}$ and the vehicle/estradiol groups. In experiment 3, groups RU486 and metestrus were extinguished 2 days after RU486/vehicle injections during metestrus, whereas group proestrus was extinguished on the morning of proestrus before vehicle administration.

Extinction recall. The test procedure was identical in all experiments. Rats were placed in context $\mathrm{B}$, and following a 1-min adaptation period, received a single $2 \mathrm{~min}$ CS presentation. In experiments 1 and 2, rats were tested for extinction recall $24 \mathrm{~h}$ after extinction training. In experiment 3 , groups RU486 and metestrus were tested $24 \mathrm{~h}$, and group proestrus was tested $72 \mathrm{~h}$, after extinction training. Thus, all rats were conditioned and tested during diestrus, and the time between conditioning and extinction recall was equivalent across groups. For an overview of the experimental timeline for all experiments, see Tables 1 and 2 .

Scoring. Rats were scored for freezing, defined as the absence of movement except that required for respiration (Fanselow, 1980), during extinction training and recall. Freezing was scored using a time-sampling procedure whereby every $3 \mathrm{~s}$ the animal was scored as 'freezing' or 'not freezing'. A percentage score was calculated for each animal to determine the proportion of total observations spent freezing. A second observer blind to the experimental condition of rats scored a random sample $(40 \%)$ of data. The inter-rater reliability across all experiments was high (average $r=0.92$ ).

Statistical analyses. In experiment 1, pre-CS freezing (during the adaptation periods before extinction training and recall) and CS-elicited freezing during extinction recall were analysed using independent samples $t$-tests, and in experiments 2 and 3, a one-way analysis of variance. Freezing during within-session extinction training was analyzed using a repeated measures analysis of variance with group as a between-subjects factor. Main effects of group were further analyzed using Student-Newman-Keuls method. Three statistical outliers were removed from the analysis - two due to their pre-CS freezing at extinction recall being $>10$ STDEVs away from the mean (from the estradiol group in experiment 1 , and the $\mathrm{E}+\mathrm{P} 6 \mathrm{~h}$ group in experiment 2 ), and one due to its CS-elicited freezing during recall being $>4$ STDEVs away from the mean (from the metestrus group in experiment 3 ).

\section{RESULTS}

\section{Experiment 1}

There were no differences between the two groups in pre-CS freezing before extinction training $\left(t_{(20)}=0.84, P=0.41\right.$; Figure 1a). During extinction training, there was a significant effect of extinction trial $\left(\mathrm{F}_{(5,100)}=29.58, P<0.0001\right)$, and no effect of group or trial-by-group interaction (F-values $<1$ ), indicating that both groups exhibited comparable conditioning and rates of extinction (Figure 1a). Both groups exhibited comparable, low, pre-CS freezing during the adaptation period before extinction recall, $\left(t_{(20)}=0.4, P=0.69\right)$, however 
Table I Experimental Timeline for Experiments $\mid$ and 2

\begin{tabular}{|c|c|c|c|c|c|c|c|}
\hline & Day I & Day 2 & Day 3 & Day 4 & Day 5 & Day 6 & Day 7 \\
\hline Experiment I & Conditioning & $\begin{array}{l}\text { Hormone } \\
\text { treatment }\end{array}$ & $\begin{array}{l}\text { Hormone } \\
\text { treatment }\end{array}$ & & Extinction training & $\begin{array}{l}\text { Extinction } \\
\text { recall }\end{array}$ & \\
\hline Vehicle & $\mathrm{CS}+$ & Vehicle & Vehicle & - & $\mathrm{CS}-$ & CS- & \\
\hline Estradiol & CS+ & Estradiol & Estradiol & - & CS- & CS- & \\
\hline \multicolumn{8}{|l|}{ Groups } \\
\hline Vehicle $(6 h)^{\mathrm{a}}$ & CS+ & Vehicle & Vehicle & - & Vehicle $\rightarrow 6 \mathrm{~h} \rightarrow \mathrm{CS}-$ & $\mathrm{CS}-$ & \\
\hline Estradiol $(6 h)^{b}$ & $\mathrm{CS}+$ & Estradiol & Estradiol & - & Vehicle $\rightarrow 6 \mathrm{~h} \rightarrow \mathrm{CS}-$ & $\mathrm{CS}-$ & \\
\hline$E+P(6 h)$ & CS+ & Estradiol & Estradiol & - & Progesterone $\rightarrow 6 \mathrm{~h} \rightarrow \mathrm{CS}-$ & CS- & \\
\hline Estradiol $(24 h)^{b}$ & CS+ & Estradiol & Estradiol & - & Vehicle & CS- & CS - \\
\hline$E+P(24 h)$ & $\mathrm{CS}+$ & Estradiol & Estradiol & - & Progesterone & CS- & $C S-$ \\
\hline
\end{tabular}

Abbreviation: CS, conditioned stimulus.

a Data were collapsed across the two vehicle groups in the final analyses.

${ }^{b}$ Data were collapsed across the two estradiol groups in the final analyses.

Table 2 Experimental Timeline for Experiment 3

\begin{tabular}{|c|c|c|c|c|c|}
\hline & Day I & Day 2 & Day 3 & Day 4 & Day 5 \\
\hline \multirow[t]{2}{*}{ Experiment 3} & (Diestrus) & (Proestrus) & (Estrus) & (Metestrus) & (Diestrus) \\
\hline & Conditioning & Drug treatment & & Extinction training & Extinction recall \\
\hline \multicolumn{6}{|l|}{ Groups } \\
\hline Metestrus & CS+ & $2 \times$ Vehicle & - & CS- & CS- \\
\hline $\mathrm{RU} 486$ & CS+ & $2 \times R \cup 486$ & - & CS- & CS- \\
\hline \multicolumn{6}{|c|}{ Drug treatment; extinction training } \\
\hline Proestrus & CS+ & $2 \times$ Vehicle; CS - & - & - & CS- \\
\hline
\end{tabular}

Abbreviation: CS, conditioned stimulus.

the groups differed significantly in CS-elicited freezing $\left(t_{(20)}=2.23, P=0.038\right)$, with estradiol-treated rats exhibiting significantly lower freezing than vehicle-treated rats (Figure 1b).

\section{Experiment 2}

There were no group differences in pre-CS freezing before extinction training $(\mathrm{F}<1$; Figure 2a). During extinction training, there was a significant effect of extinction trial $\left(\mathrm{F}_{(5,275)}=53.87, P<0.0001\right)$, and no effect of group or trialby-group interaction ( $\mathrm{F}$-values $<1$ ), indicating that all groups exhibited comparable conditioning and rates of extinction (Figure 2a). All groups exhibited comparable, low, pre-CS freezing during the adaptation period before extinction recall, $(\mathrm{F}<1)$, however the groups differed significantly in CS-elicited freezing $\left(\mathrm{F}_{(3,58)}=11.39, P<0.0001\right.$; Figure $\left.2 \mathrm{~b}\right)$. Post hoc tests indicated that group estradiol exhibited significantly lower freezing relative to group vehicle (replicating the findings from experiment 1) as well as group E+P $24 \mathrm{~h}$, whereas group E+P $6 \mathrm{~h}$ exhibited significantly lower freezing than all other groups $(P$-values $<0.05)$.

To ensure that the differences in CS-elicited freezing at extinction recall between the $\mathrm{E}+\mathrm{P} 6 \mathrm{~h}$ and $\mathrm{E}+\mathrm{P} 24 \mathrm{~h}$ groups were not merely due to the difference in time interval between fear conditioning and extinction recall, we conducted several post-hoc tests. First, we conducted a $2 \times 2$ analysis of variance on the vehicle and estradiol sub-groups. In this analysis, the first factor corresponded to drug condition (vehicle or estradiol) and the second factor corresponded to time interval between final injection and extinction training $(6$ or $24 \mathrm{~h})$. This analysis revealed a significant main effect of drug condition $\left(\mathrm{F}_{(1,32)}=7.01\right.$, $P=0.013$ ), with no main effect of time interval or interaction between the two factors $(P$-values $>0.6)$. Thus, in vehicle and estradiol-treated rats, time interval alone did not influence 

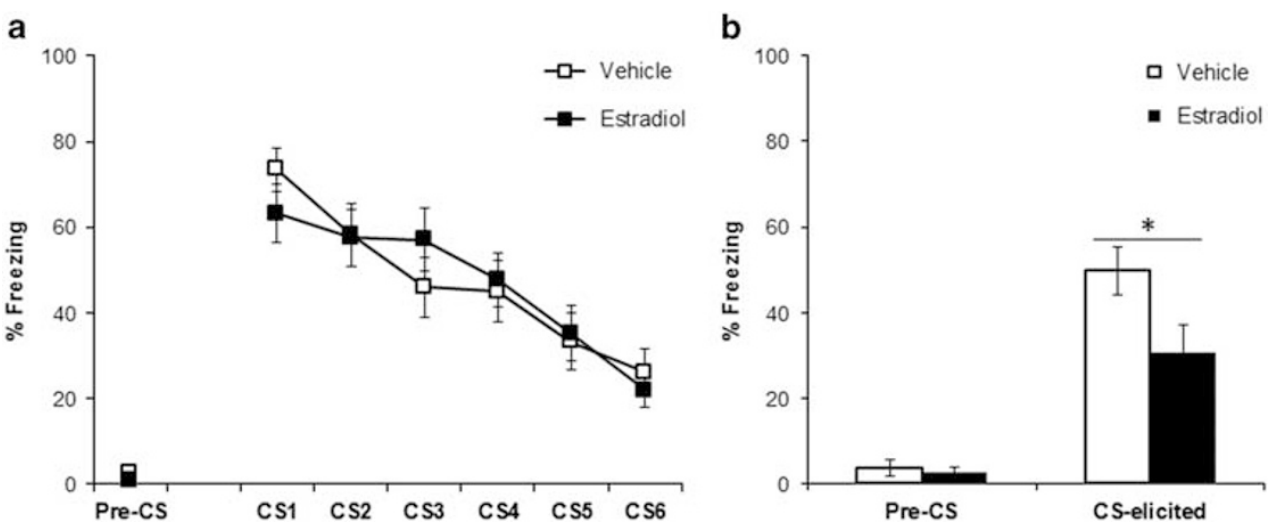

Figure I (a) Mean $( \pm$ SEM) pre-CS, and CS-elicited, freezing for groups vehicle $(n=\mid I)$ and estradiol $(n=\mid I)$ during extinction training in experiment I. (b) Mean $( \pm$ SEM) pre-CS, and CS-elicited, freezing during test for groups during extinction recall in experiment I. $*$ Estradiol $<$ vehicle $(P<0.05)$.
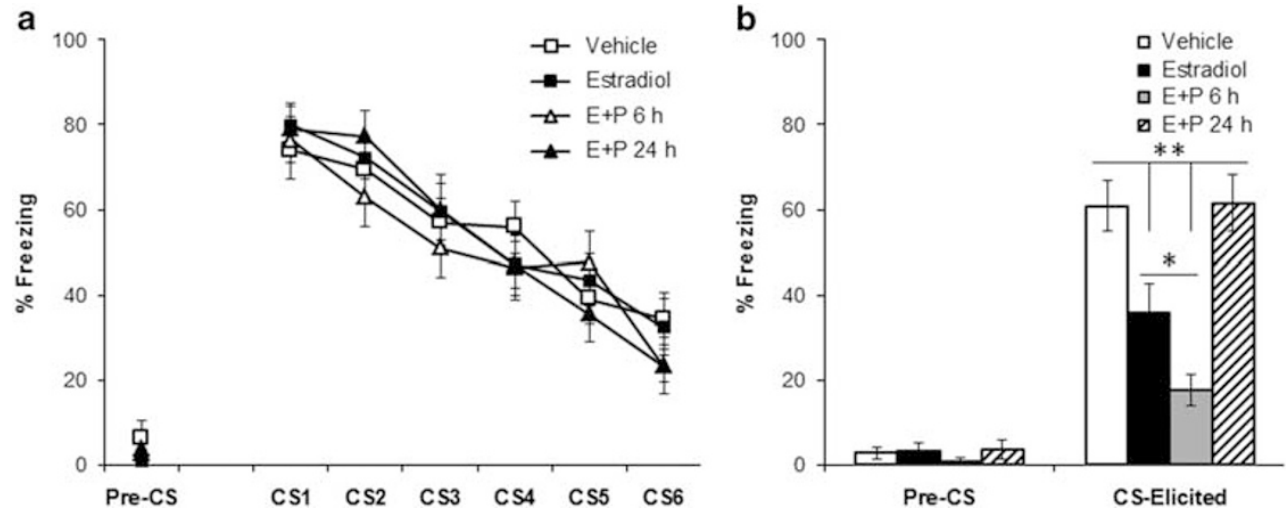

Figure 2 (a) Mean $( \pm$ SEM) pre-CS, and CS-elicited, freezing for groups vehicle $(n=16)$, estradiol $(n=16), E+P \quad h \quad(n=13)$, E+P $24 \mathrm{~h}(n=14)$ during extinction training in experiment 2. (b) Mean $( \pm$ SEM) pre-CS, and CS-elicited, freezing for groups during test for extinction recall in experiment 2 . *E+P $6 \mathrm{~h}<$ estradiol $(P<0.05)$, **estradiol and $\mathrm{E}+\mathrm{P} 6 \mathrm{~h}<$ vehicle and $\mathrm{E}+\mathrm{P} 24 \mathrm{~h}(P<0.05)$.
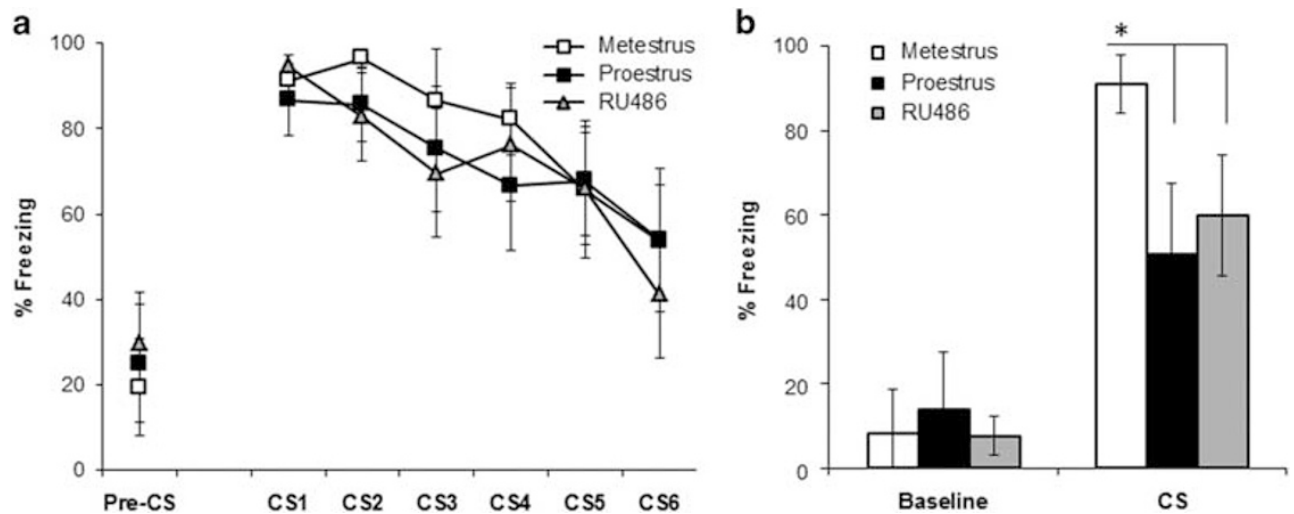

Figure 3 (a) Mean $( \pm$ SEM) pre-CS, and CS-elicited, freezing for groups metestrus $(n=9)$, proestrus $(n=10)$, and RU486 $(n=1 \mathrm{I})$ during extinction training in experiment 3. (b) Mean ( \pm SEM) pre-CS, and CS-elicited, freezing for groups during test for extinction recall in experiment 3. *Proestrus and $\mathrm{R} \cup 486<$ metestrus $(P<0.05)$.

CS-elicited freezing at extinction recall (Supplementary Figure S1B). Furthermore, we compared the $\mathrm{E}+\mathrm{P} 24 \mathrm{~h}$ group to the two estradiol sub-groups (ie, E $6 \mathrm{~h}$, which had the same conditioning-extinction recall interval as the $\mathrm{E}+\mathrm{P} 6 \mathrm{~h}$ group, and $\mathrm{E} 24 \mathrm{~h}$, which had the same conditioningextinction recall interval as the $\mathrm{E}+\mathrm{P} 24 \mathrm{~h}$ group), and in both cases, there was a significant difference ( $P$-value$\mathrm{s}<0.04)$. Together, this suggests that the impaired extinction recall in the $\mathrm{E}+\mathrm{P} 24 \mathrm{~h}$ group relative to the $\mathrm{E}+\mathrm{P} 6 \mathrm{~h}$ group was not due to the difference in time interval between conditioning and extinction recall.

\section{Experiment 3}

There were no group differences in pre-CS freezing before extinction training $(\mathrm{F}<1$; Figure 3a). During extinction 
training, there was a significant effect of extinction trial $\left(\mathrm{F}_{(5,135)}=12.68, P<0.0001\right)$, and no effect of group or trialby-group interaction ( $\mathrm{F}$-values $<1$ ), indicating that all groups exhibited comparable conditioning and rates of extinction (Figure 3a). All groups exhibited comparable, low, pre-CS freezing during the adaptation period before extinction recall, $(\mathrm{F}<1)$, however the groups differed significantly in CS-elicited freezing $\left(\mathrm{F}_{(2,29)}=4, P=0.03\right.$; Figure $\left.3 \mathrm{~b}\right)$. Post hoc tests indicated that the proestrus and RU486 groups exhibited significantly lower freezing relative to the metestrus group $(P<0.05)$.

\section{DISCUSSION}

The present experiments demonstrate that estradiol alone facilitates fear extinction in OVX rats. This effect was potentiated by progesterone when extinction training occurred $6 \mathrm{~h}$ following progesterone administration. Conversely, estradiol-induced facilitation of fear extinction was abolished by progesterone if extinction training occurred $24 \mathrm{~h}$ following progesterone administration. The present experiments are the first to systematically isolate the impact of the various hormonal changes across the estrous cycle on fear extinction. On the basis of our findings in OVX rats, we infer that in the naturally cycling female, increases in estradiol may be responsible for the enhancement in fear extinction during proestrus. Conversely, the impact of increasing progesterone levels is likely time-dependent: augmenting estradiol's facilitation of fear extinction within $6 \mathrm{~h}$, but rapidly reversing this within $24 \mathrm{~h}$. This inference is supported by the outcome of the third experiment, which demonstrated that preventing progesterone receptor activation during proestrus rescued the impairment in extinction recall in rats extinguished during metestrus. Together, these experiments suggest that during the estrous cycle, whereas estradiol mediates enhancements in fear extinction observed during proestrus, progesterone ultimately mediates the impairments in fear extinction observed during metestrus.

The present findings on fear extinction are broadly consistent with past research illustrating that progesterone antagonizes estradiol's effects in other domains of learning and memory. For example, in estradiol-treated OVX rats, progesterone augmented the beneficial effect of estradiol on spatial memory when administered 90 min before test, but reversed estradiol's effects when administered $24 \mathrm{~h}$ before test (Sandstrom and Williams, 2001). Likewise, chronic estradiol administration enhanced spatial memory in OVX middle-aged rats, and this was prevented by coadministration of chronic progesterone (Bimonte-Nelson et al, 2006). Similarly, in OVX mice, a low dose of progesterone co-administered with estradiol prevented the enhancement in object recognition caused by estradiol alone (Harburger et al, 2009). In addition to its impact on estradiol-induced increases in dendritic spines, progesterone has been shown to reverse several other physiological consequences of chronic estradiol administration, including enhanced neuroprotection following brain injury (Rosario et al, 2006), and increases in neurotrophic factors BDNF, NGF, and NT3 (Bimonte-Nelson et al, 2004). Progesterone also prevents acute physiological effects of estradiol, including rapid phosphorylation of extracellular-signal regulated kinase (Harburger et al, 2009), and CREB (Murphy and Segal, 2000). The exact mechanisms by which progesterone antagonizes estradiol's behavioral and physiological effects are unclear, although in cultured hippocampal cells progesterone prevents estradiol-induced dendritic spine formation through conversion to its metabolite, the neurosteroid tetrahydroprogesterone (Murphy and Segal, 2000). As tetrahydroprogesterone potentiates $\mathrm{GABA}_{\mathrm{A}}$ receptor activity, it is possible that GABA-mediated increases in neuronal inhibition may reverse estradiol-facilitated increases in neuronal excitation. It remains to be tested whether similar downstream processes mediate progesterone's reversal of estradiol-facilitated extinction.

We and others have previously demonstrated that estradiol and progesterone facilitate fear extinction when administered just before or immediately after extinction training (Milad et al, 2009; Zeidan et al, 2011; Graham and Milad, 2013). This facilitation is very likely due to non-genomic effects of these hormones on cell signaling and excitability via membrane bound receptors. In the present experiments, however, extinction training took place $48 \mathrm{~h}$ after estradiol administration and either 6 or $24 \mathrm{~h}$ after progesterone administration. This is beyond the time points by which these hormones are metabolized and it is therefore unlikely that the facilitation in fear extinction was due to an acute impact of estradiol and/or progesterone on signaling processes underlying long-term memory formation (eg, phosphorylation of extracellular-signal regulated kinase and CREB, or upregulation of neurotrophic factors). Instead, our results strongly suggest that the influence of estradiol and progesterone on fear extinction in OVX rats was due to the longer-term, genomic consequences of these hormones, and in turn, this raises the possibility that fluctuations in fear extinction during the estrous cycle may be mediated, at least in part, by similar mechanisms. One candidate genomic mechanism relates to hormone-induced alterations in basal dendritic spine density. Our experiments provide indirect evidence for this proposition; extinction training was precisely timed to occur during periods of low, intermediate, or high densities of dendritic spines, based on wellestablished prior research by Woolley and McEwen (1993), and our findings demonstrated that extinction recall was exactly proportional to the expected spine densities during extinction training. That is, optimal extinction recall was achieved by matching extinction training to the time point at which spine densities were expected to be greatest (ie, $6 \mathrm{~h}$ post-progesterone administration in estradiol-treated rats), whereas return of fear during extinction recall was observed when extinction training was matched to the time point at which spine densities were expected to be lowest (ie, $24 \mathrm{~h}$ post-progesterone administration in estradiol-treated rats). Moreover, by blocking progesterone receptor activation during proestrus, a manipulation which has been demonstrated to prevent the cyclic collapse of dendritic spines, extinction recall in metestrus rats (that normally exhibit return of fear) was spared. Dendritic spines have a role in long-term memory formation (Leuner and Shors, 2004), and it has recently been demonstrated that fear extinction causes new spine formation within the prefrontal cortex, the levels of which are positively correlated with extinction recall (ie, reduced fear expression; Lai et al, 2012). Although the relationship between hippocampal spine density and fear 
extinction has not been investigated, it could be speculated that hormonal-induced increases or decreases in basal dendritic spine density could create a neuronal environment that is more or less permissive, respectively, for the consolidation of fear extinction. This possibility needs to be examined in future research that combines behavioral and morphological analyses.

Fear extinction is the laboratory basis of exposure therapy for anxiety disorders, and identical cyclic fluctuations in fear extinction to those observed in female rats have been documented to occur throughout the menstrual cycle in healthy women (eg, Milad et al, 2010; Graham and Milad, 2013) as well as in women with posttraumatic stress disorder (Glover et al, 2012). The implication of these findings is that exposure therapy may be less effective in women during periods of low hormonal levels. It has been suggested that estradiol, on its own or in combination with progesterone, may be a potentially useful pharmacological adjunct to augment the beneficial effects of exposure therapy in women (Milad et al, 2010; Glover et al, 2012; Graham and Milad, 2013). Indeed, in women who have not undergone hysterectomy, long-term estradiol treatment (as would need to occur for more complex anxiety disorders requiring multiple exposure sessions) must be accompanied by progesterone. The present findings suggest that although optimal therapeutic benefit could be achieved via an adjunct that includes both estradiol and progesterone, unless the timing of treatment relative to hormone administration is carefully controlled, progesterone may antagonize the effects of estradiol and prevent its benefit altogether. We have already demonstrated that a single dose of estradiol alone enhances fear extinction in healthy women (Graham and Milad, 2013); further studies are now needed to assess whether co-administration of estradiol and progesterone has similar biphasic effects on fear extinction in humans. Such studies may prove useful in identifying the most effective means by which hormone-based pharmacological adjuncts could be implemented to optimize treatments for anxiety disorders.

\section{FUNDING AND DISCLOSURE}

This work was supported by an Australian Research Council Discovery Early Career Research Award (DE140100243) and a UNSW Australia early career research grant to BMG. The authors declare no conflict of interest.

\section{REFERENCES}

The Australian Code of Practice for the Care and Use of Animals for Scientific Purposes (7th edn). (2004). Retrieved from http://www.nhmrc.gov.au/publications/synopses/ea16syn.htm.

Becker JB, Arnold AP, Berkley KJ, Blaustein JD, Eckel LA, Hampson E et al (2005). Strategies and methods for research on sex differences in brain and behavior. Endocrinology 146: 1650-1673.

Bimonte-Nelson HA, Francis KR, Umphlet CD, Granholm AC (2006). Progesterone reverses the spatial memory enhancement initiated by tonic and cyclic oestrogen therapy in middle-aged ovariectomized female rats. Eur J Neurosci 24: 229-242.
Bimonte-Nelson HA, Nelson ME, Granholm AC (2004). Progesterone counteracts estrogen-induced increases in neurotrophins in the aged female rat brain. Neuroreport 15: 2659-2663.

Chang YJ, Yang CH, Liang YC, Yeh CM, Huang CC, Hsu KS (2009). Estrogen modulates sexually dimorphic contextual fear extinction in rats through estrogen receptor beta. Hippocampus 19: $1142-1150$.

Fanselow MS (1980). Conditional and unconditional components of postshock freezing. The Pavlov J Biol Sci 15: 177-182.

Glover EM, Jovanovic T, Mercer KB, Kerley K, Bradley B, Ressler KJ et al (2012). Estrogen levels are associated with extinction deficits in women with posttraumatic stress disorder. Biol Psychiatry 72: 19-24.

Graham BM, Milad MR (2011). The study of fear extinction: implications for anxiety disorders. Am J Psychiatry 168: 1255-1265.

Graham BM, Milad MR (2013). Blockade of estrogen by hormonal contraceptives impairs fear extinction in female rats and women. Biol Psychiatry 73: 371-378.

Gruene TM, Roberts E, Thomas V, Ronzio A, Shansky RM (2015). Sex-specific neuroanatomical correlates of fear expression in prefrontal-amygdala circuits. Biol Psychiatry 10.1016/j.biopsych.2014.11.014.

Harburger LL, Saadi A, Frick KM (2009). Dose-dependent effects of post-training estradiol plus progesterone treatment on object memory consolidation and hippocampal extracellular signalregulated kinase activation in young ovariectomised mice. Neuroscience 160: 6-12.

Lai CS, Franke TF, Gan W-B (2012). Opposite effects of fear conditioning and extinction on dendritic spine remodelling. Nature 483: 87-91.

Leuner B, Shors TJ (2004). New spines, new memories. Mol Neurobiol 29: 117-130.

Milad MR, Igoe SA, Lebron-Milad K, Novales JE (2009). Estrous cycle phase and gonadal hormones influence conditioned fear extinction. Neuroscience 164: 887-895.

Milad MR, Zeidan MA, Contero A, Pitman RK, Klibanski A, Rauch SL et al (2010). The influence of gonadal hormones on conditioned fear extinction in healthy humans. Neuroscience 168: 652-658.

Murphy DD, Segal M (2000). Progesterone prevents estradiolinduced dendritic spine formation in cultured hippocampal neurons. Neuroendocrinology 72: 133-144.

Rey CD, Lipps J, Shansky RM (2014). Dopamine D1 receptor activation rescues extinction impairments in low-estrogen female rats and induces cortical layer-specific activation changes in prefrontal amygdala circuits. Neuropsychopharmacology 39: 1282-1289.

Rosario ER, Ramsden M, Pike CJ (2006). Progestins inhibit the neuroprotective effects of estrogen in rat hippocampus. Brain Res 1099: 206-210.

Sandstrom NJ, Williams CL (2001). Memory retention is modulated by acute estradiol and progesterone replacement. Behav Neurosci 115: 384-393.

Woolley CS, McEwen BS (1993). Roles of estradiol and progesterone in regulation of hippocampal dendritic spine density during the estrous cycle in the rat. J Comp Neurol 336: 293-306.

Zeidan MA, Igoe SA, Linnman C, Vitalo A, Levine JB, Klibanski A et al (2011). Estradiol modulates medial prefrontal cortex and amygdala activity during fear extinction in women and female rats. Biol Psychiatry 70: 920-927.

Supplementary Information accompanies the paper on the Neuropsychopharmacology website (http://www.nature.com/npp). 